\title{
Search strategies in rural and urban environment during natal dispersal of the red squirrel
}

\author{
Suvi Hämäläinen ${ }^{1,2}$ (D) Karen Fey $^{1} \cdot$ Vesa Selonen $^{1}$ \\ Received: 3 April 2020 / Revised: 2 September 2020 / Accepted: 9 September 2020 / Published online: 18 September 2020 \\ (C) The Author(s) 2020
}

\begin{abstract}
Decisions made during natal dispersal highly influence the future fitness of the animal. The selection of future home range affects, for example, food supply and mating success. In order to select between potential sites, dispersing individuals may use different search strategies, and for example, aim to compare quality of different sites by revisiting them. Alternatively, dispersers visit new sites without comparison until a suitable site is located. By using radio telemetry, we studied search strategies during natal dispersal in both urban and rural environments. We examined what kind of sites juvenile red squirrels (Sciurus vulgaris) choose as their home range from all visited sites and whether they display revisit behavior during natal dispersal. We found that most of the dispersing individuals perform revisits while searching for the settlement site. In the rural study area, there were also individuals (mostly long-distance dispersers) that did not perform revisits and settled in the last visited area. The landscape characteristics did not explain the amount of revisits individuals made, but the amount of revisits declined with site's distance to natal nest and dispersal distance of individuals. The effect of landscape characteristics on settlement decision was small, but surprisingly, juvenile red squirrels in the rural area settled in sites with more built area compared with sites only visited. However, the decision-making of red squirrels during natal dispersal seems to be driven mainly by other factors (potentially food availability and conspecific density) than landscape characteristics. We conclude that revisiting behavior is linked to dispersal strategy of red squirrels and can differ between the sexes and habitats of the species.
\end{abstract}

\section{Significance statement}

Animals often choose their habitat from among multiple alternative habitats and potential settlement sites, and the decisions made during dispersal highly influence the future fitness of the animal. We examined what kind of areas juvenile red squirrels choose as their home range in both urban and rural environments and whether they display revisit behavior when selecting their home range from many alternatives. We found that search strategies during natal dispersal can vary between individuals and habitats. Surprisingly, juvenile red squirrels in the rural area settled in sites with more built area compared with the sites only visited. However, for red squirrel, decisions made by juveniles during the search of a home range are mainly influenced by other factors than landscape composition.

Keywords Natal dispersal $\cdot$ Eurasian red squirrel $\cdot$ Movements $\cdot$ Prospecting $\cdot$ Landscape ecology $\cdot$ Decision-making

Communicated by E. Korpimäki

Suvi Hämäläinen

sphama@utu.fi

1 Department of Biology, Section of Ecology, University of Turku, FI-20014 Turku, Finland

2 Turku, Finland

\section{Introduction}

Animals often choose their habitat from among multiple alternative habitats and potential settlement sites (Luttbeg 2002). In many mammals, habitat selection takes place during natal dispersal, when juveniles abandon their mother's home range (Clobert et al. 2001). Thus, the decisions made during this process highly determine the future fitness of the individual, that is, survival and mating success (Bowler and Benton 2005). Juvenile dispersers are also good model organisms to study decision-making, because we can be sure that they are 
interpreting habitat cues for the first time in their life (Mabry and Stamps 2008). The study of habitat selection through decision-making process helps us to understand the costs of habitat selection and the search abilities of animals (Abrahams 1986; Haughland and Larsen 2004; Luttbeg and Langen 2004).

Dispersal decisions are affected by landscape characteristics, predation risk, and competition (Bonte et al. 2012; Cote et al. 2017). In order to be able to select optimally, animals need to assess the quality of different sites. At the same time, individuals need to balance between the costs of searching new sites with the uncertainty related to the quality of these sites compared with those already visited (Luttbeg 2002; Bonte et al. 2012; Nurmi et al. 2017). To evaluate quality of different sites, dispersing individuals are observed to compare potential sites by revisiting, that is, the individual returns to the already visited sites (Mabry and Stamps 2008; Selonen and Hanski 2010). Frequent revisits to a certain site are thought to help ensure the quality of the site (Luttbeg and Langen 2004; Mabry and Stamps 2008). However, only few studies have documented revisit behavior, as animals most often visit each area only once before making the settlement decision (e.g., Dale et al. 2006). There may also be individual variation in the dispersal behavior (Dingemanse et al. 2003), and the search strategies used by individuals during natal dispersal can be affected by external factors. For example, the distance between visited sites likely decreases revisiting probability (Selonen and Hanski 2010). The study of dispersal has long suffered from the scarcity of research focusing on search phase of dispersal, because the settlement patterns are much easier to document than the search phase (Stamps 2001). However, the study of search strategies (like the revisiting behavior) can help to better predict the dispersal patterns and increase the understanding of the process leading into settlement.

Evaluating the quality of a certain site may be complicated, because environmental cues the individual uses to select the suitable site can sometimes be false, leading to suboptimal habitat selection (Schlaepfer et al. 2002). The use of environmental cues may be disturbed, for example, by fragmentation of habitat, if it affects movement ability and thus decisionmaking process of individuals (Wauters et al. 2010). In addition, urbanization modifies the landscape composition and alters the costs of moving in the landscape (Bonte et al. 2012) and the quality of the habitat, for example, in the form of new resources, like artificial nest structures (Jokimäki et al. 2017). Consequently, the dispersal behavior may differ between urban and rural landscapes (Hämäläinen et al. 2019), which may also affect the search strategies of individuals in these habitats.

In this paper, we study search strategies of radio-collared juvenile Eurasian red squirrels (Sciurus vulgaris, hereafter called "red squirrel") when individuals are dispersing from their natal home range to the place of settlement. Red squirrels are particularly interesting for study of dispersal behavior, because they are dependent on trees, and consequently, their habitats (forests) are often heavily fragmented. Studying search strategies of such animals can help to understand, how dispersers cope in moving in fragmented landscapes. Specifically, we investigated (1) whether or not dispersers perform revisit behavior, and the amount of revisits to different sites during natal dispersal in both urban and rural environment; and (2) how landscape characteristics, such as built environment or fields, affect this decision-making process by (a) comparing the sites that were selected for settlement and the sites that were only visited during dispersal. We also (b) examined if the amount of revisits is connected to landscape characteristics of the site, dispersal distance, sex of the individual, or study area (urban versus rural). We hypothesize that juvenile individuals compare different potential sites for the future home range. We also anticipate the landscape characteristics to affect the final settlement decisions, as landscape can affect the quality of an area and thus influence future fitness of the individual.

\section{Materials and methods}

\section{Study area and data collection}

We collared and monitored juvenile red squirrels in two study areas in Finland. The first study area was the Kauhava, Lapua, and Lappajärvi region in rural Southern Ostrobothnia (hereafter called "The Kauhava study area"). In this area, the landscape is consisted with a mosaic of mainly managed boreal forest areas separated by large agricultural areas, dominant tree species being Norway spruce (Picea abies) and Scots pine (Pinus sylvestris). This area is sparsely populated and settlement consists mainly of detached houses.

The second study area was the city of Turku, in southwestern Finland, with 180,000 inhabitants and a landscape consisting of heavily built grid plan areas with multi-storey buildings, small wooded park areas, and private gardens. The main tree species in the city area are elm (Ulmus glabra) and lime tree (Tilia sp.), but isolated patches of coniferous trees, such as Scots pine (Pinus sylvestris) and European spruce (Picea abies) also grow in park areas. In the rural Kauhava area, the main predators of red squirrel are goshawk (Accipiter gentilis) and pine marten (Marten marten), whereas in the urban area those occur in low number and do not pose a threat to the species (Jokimäki et al. 2017). Feral cats and foxes are more abundant in the cities than in the rural environment (Baker and Harris 2007) and may pose a threat especially for juvenile red squirrels.

During 2012-2015, we caught juveniles from May to July (depending on area) with nets from nest boxes and cavities or 
with live traps set on the ground, and fitted them with radio collars weighing 5 or $8 \mathrm{~g}$ (Biotrack, UK). After collaring, animals were immediately released at the place of capture. At the time of capture, juvenile red squirrels weighed on average $133 \pm 44$ (SD) $g$ in the Kauhava study area and $178 \pm 48$ (SD) $\mathrm{g}$ in Turku, and were approximately 1.5 to 2 months old. At this age, red squirrels have not yet accomplished dispersal movements but move in close proximity of their birth place. Body mass at capture did not affect observed dispersal distances (Selonen et al. 2018a; for more information on our data, see Fey et al. 2016; Hämäläinen et al. 2019). After collaring, individuals were followed with portable receiver (Biotrack) and Yagi antenna. The locations of juveniles were gathered both daytime and after dusk, to attain both movement locations and nest site locations. The tracking was carried out from early June to late September approximately five times a week. After dispersal period, the tracking was continued in the Turku study area through the following winter by 1 - to 2week intervals, and in Kauhava area until the end of the year by 1 - to 3 -week intervals. It was not possible to record data blind because our study involved focal animals in the field. In total, there were an average of $63 \pm 7$ locations per individual in the Turku area and $33 \pm 22$ in the Kauhava area.

\section{Landscape data}

Landscape maps were constructed in order to study the effect of landscape composition on behavior and decisions during natal dispersal. In the Turku study area, landscape was divided into the following land-use classes: deciduous trees; coniferous trees; shrub or grass; waterway; building; and asphalt, gravel, or sand (hereafter called "asphalt"). The landscape map was created by manually digitizing these land-use classes on top of an aerial photograph (National Land Survey of Finland, 2008, ETRS-TM35FIN, minimum mapping unit 1 $\mathrm{m}$, terrain resolution $0.5 \mathrm{~m}$ ). In the Kauhava study area, the landscape map $(25 \times 25 \mathrm{~m}$ pixel grid) was based on Landsat images, SLICE dataset and forest classifications from 1997 and 2009 (see Morosinotto et al. 2017 for further information of map construction, we updated the landscape map for new clear-cuts). There, the landscape was divided into the following classes: young forest (inc. clear-cuts), birch-dominated forest, pine-dominated forest, spruce-dominated forest, built landscape (inc. buildings and roads), field, and water. Landscape characteristics for each squirrel observation point were calculated from these land-use maps using a 25-m radius buffer around location points $(25 \mathrm{~m}$ being the minimum possible radius allowed by the pixel size of the landscape data). From these observation points, we calculated the average landscape for each visited site separately for each individual. For each visited site, we also calculated edge density which represents the relationship between the size of a forested area and the amount of habitat edge. Also, the Euclidean distance from the center of the site to the natal nest was calculated for each site.

\section{Movement data: visits, revisits, and dispersal distance}

The natal site was determined to be the woodlot where the juvenile squirrel was caught and collared. The visited sites outside natal site (300-m cutoff distance) were divided to sites used for settlement and to sites only visited before settlement. The cutoff value of $300 \mathrm{~m}$ was selected to correspond double the radius of the observed average home range size, being 7 ha (Hämäläinen et al. 2018). The settlement site was determined to be the last area where the red squirrel was observed until the end of the tracking period (Hämäläinen et al. 2018, 2019). After the settlement, the individual did not visit new sites and the movement distances between consecutive points were shortened.

The sites the individual visited during its dispersal were defined as separate areas if there was a road, field, clear cut, or other significant barrier for movement between the woodlots, or if there was more than 300-m distance between the red squirrel observation points. Revisits were visits to a site that had been already visited before, and between the visit and revisit, there was a location to some other site, including visits to natal site. That is, between separate visits, the individual had to change sites (i.e., leave the site to visit some other site or natal area). Therefore, if there were multiple locations in a row within one site, those were considered only one visit.

The time spent for dispersal period was calculated as the number of days a juvenile red squirrel spent searching for a settlement area. The dispersal period was determined to start when a juvenile left the natal range for the first time. After the start of dispersal, it is possible that individuals returned to visit the natal home range while searching for the possible future home ranges. The end of the dispersal period was determined to be the first observation at the settlement area after which an individual did not visit other areas. Juveniles were considered to have settled in an area when they no longer visited new possible sites, and the movement distances between consecutive points were clearly shortened.

We calculated the dispersal distance as a straight-line distance between the first observed nest where the juvenile was located after collaring and the last observed nest after dispersal period. We included only the red squirrels that survived until the end of the dispersal period (determined to be 15 September) except in the case of three Kauhava individuals, where the red squirrels had already dispersed multiple kilometers from their natal site and either disappeared or were killed during the dispersal movements, leading to 18 individuals in Turku (11 males and 7 females) and 22 individuals in the Kauhava area (10 males and 12 females). For the analysis of revisits in relation to dispersal distance, we excluded individuals with less than 10 location points, in order to be sure that 
we could observe revisits (these were 8 individuals from Kauhava year 2012 and one individual from Turku; in 2012, we did not concentrate following individuals during the search phase of the dispersal). After this, we had revisit data for 17 individuals in Turku (10 males and 7 females) and 14 in Kauhava ( 8 males and 6 females) (for these individuals, there were at least 41 locations per individual).

\section{Analyses}

We examined if the amount of revisits is dependent on the dispersal distance. We included the data from both of our study areas to create a binomial model, with the event/trial response (event $=$ number of revisits made by individual, trial $=$ total number of visits made by individual). We set the dispersal distance as continuous explanatory variable, and study area and the sex of the individual as class variables in the model. For this analysis, we used information on the dispersal distance of 17 individuals from Turku and of 14 from the Kauhava study area (see above). All the analyses were performed by using SAS 6.1 .

To study if the amount of revisits is related to habitat composition of the site (Turku $n=113$, Kauhava $n=81$ sites, for 31 individuals), we performed models with individual's ID as repeated measure (general estimating equations, GLIMMIX). These models were done separately for Turku and Kauhava study areas. For the Turku area, the response variable was the number of revisits (gamma distribution) made to the site, and explanatory variables were land-use classes and the distance of the site from individual's natal nest. Whether the site was used for settlement or not was included as class variable in the model. In addition, sex and total number of visits by individuals were included in the model. We conducted a separate model for land-use class asphalt to attain variance inflation factor (VIF) under four for every variable. For the Kauhava area, the response variable was binomial: the area being revisited or not, because the number of revisits remained low within this study area. The explanatory variables were similar as above for the model for Turku study area. In order to attain VIF under four, we performed separate model for land-use class field in Kauhava region.

Finally, we made a binary model to study if selection of site for settlement is related to the landscape composition of the site (GLIMMIX). Information about the site being selected or only visited was the response variable, while the amount of revisits and different land-use classes in each site were explanatory variables, individual ID being a repeated measure (general estimating equations, GLIMMIX). Sex was included as a class variable in the model. We made separate models for the study areas in Kauhava and Turku. Due to collinearities, we performed separate models for the habitat variables "open area" in Kauhava and "deciduous forest" in Turku study area, and thus attained VIF values under four for each variable.

\section{Results}

Red squirrels spent on average $51 \pm 22$ (SD) days in the Kauhava study area and $50 \pm 22$ (SD) days in Turku area to find their settlement sites (Table 1). In the urban Turku, all 20 examined individuals performed revisits during dispersal, whereas in Kauhava area, 10 individuals made revisits and 8 individuals visited each site only once. In Turku, an average of $62 \%$ of the visits were considered revisits, whereas in Kauhava, there were significantly less revisits, $23 \%$ (Tables 1, 2).

The probability to perform revisits declined with increasing dispersal distance (Table 2, Fig. 1). There was also a difference in revisits between sexes: male juvenile red squirrels performed more revisits than females (Table 2).

In both Kauhava and Turku study areas, the number of revisits made to the site was not related to landscape variables of the site (Table 3). In both study areas, red squirrels made more revisits to the sites that were close to their natal nest (Table 3), and more revisits were made to the site where the individual settled (Table 3). In rural Kauhava, juvenile red squirrels settled in sites where there, surprisingly, was more built area compared with sites not selected (Table 4). In urban Turku, we found no difference in landscape characteristics between selected sites and only visited sites (Table 4).

\section{Discussion}

We observed that in both urban and rural areas, dispersing juvenile red squirrels performed revisit behavior while searching for their home range. Similar observations have been made earlier for example for dispersing brush mice (Peromyscus boylii, Mabry and Stamps 2008). Mabry and Stamps (2008) assumed that if the number of revisits was higher than $5 \%$ of the total number of visits the individual had made, the revisits have not been made only by mistake (called as comparative Bayes dispersal rule, Luttbeg 2002; Mabry and Stamps 2008; Selonen and Hanski 2010). In our case, all individuals in Turku and 10 out of 18 individuals in Kauhava performed more revisits than $5 \%$ of their visits in total.

The revisit behavior, however, varied between individuals as females revisited less than males and red squirrels with longer dispersal distance made less revisits than shortdistance dispersers. There is a major difference in dispersal distances between the two study areas, average distances with standard deviation being in Turku $431 \pm 363 \mathrm{~m}$ and $3638 \pm$ $3774 \mathrm{~m}$ in Kauhava (Hämäläinen et al. 2019). But even though the study area was taken into account in the models, we found a significant difference in the amount of revisits between short- and long-distance dispersers. When individuals do not use revisit behavior to compare potential settlement sites, the prevailing rule for settlement may base on 
Table 1 The data (average $\pm \mathrm{SD}$ ) used to describe search strategies during natal dispersal of juvenile red squirrels

\begin{tabular}{|c|c|c|c|c|}
\hline & \multicolumn{2}{|l|}{ Turku } & \multicolumn{2}{|l|}{ Kauhava } \\
\hline & Male & Female & Male & Female \\
\hline Number of visited areas & $5.9 \pm 3.6$ & $6.3 \pm 3.4$ & $3.8 \pm 2.5$ & $5.2 \pm 3.9$ \\
\hline Sexes combined & \multicolumn{2}{|c|}{$6.1 \pm 3.3$} & \multicolumn{2}{|c|}{$4.1 \pm 3.0$} \\
\hline Number of visits outside natal area & $20.5 \pm 10.6$ & $14.7 \pm 6.3$ & $6.0 \pm 5.2$ & $5.4 \pm 3.3$ \\
\hline Sexes combined & \multicolumn{2}{|c|}{$18.5 \pm 9.2$} & \multicolumn{2}{|c|}{$6.4 \pm 4.7$} \\
\hline Percentage of visits being revisits & $65.7 \pm 14.8$ & $58.8 \pm 10.9$ & $24.4 \pm 24.5$ & $22.6 \pm 30.3$ \\
\hline Sexes combined & \multicolumn{2}{|c|}{$62.2 \pm 14.9$} & \multicolumn{2}{|c|}{$23.3 \pm 23.5$} \\
\hline Time used for prospecting period, days & $58 \pm 23$ & $37 \pm 18$ & $50 \pm 29$ & $49 \pm 7$ \\
\hline Sexes combined & \multicolumn{2}{|c|}{$50 \pm 22$} & \multicolumn{2}{|c|}{$51 \pm 22$} \\
\hline
\end{tabular}

some quality threshold that needs to be met before settlement decision (Luttbeg and Langen 2004; Mabry and Stamps 2008). The connection between long-dispersal distances and fewer revisits performed may be cost-related, long-distance dispersers needing to move longer to make revisits to earlier visited sites (Selonen and Hanski 2010). Selonen and Hanski (2010) found a similar pattern of revisit percentage declining with increasing dispersal distance in flying squirrel (Pteromys volans). This may suggest that the behavioral difference between short-distance dispersers with several revisits to potential settlement sites and long-distance dispersers without such a comparative behavior may be common for dispersers of different species (see also e.g., Reed et al. 1999; Danchin et al. 2001), or at least in arboreal squirrels.

The studied red squirrel juveniles preferred to settle near built areas in the rural Kauhava study area. This is an interesting result, because recently, it has been noticed that the abundance of red squirrels is increasing in cities and near human settlement (Jokimäki et al. 2017), whereas the populations have been found declining in many rural regions in Finland and northwest Russia (Turkia et al. 2018). Thus, our result may support the evidence that red squirrels thrive near human settlement. The major food item of red squirrels in boreal forests is spruce (Picea abies) seeds, the abundance of which fluctuates greatly from year to year. Also, cone crops may be less plentiful in managed forests, like the ones in the Kauhava

Table 2 The effect of dispersal distance ( $n=17$ for Turku, $n=14$ for Kauhava), study area (class variable: Turku vs. Kauhava) and sex (class variable: male vs. female) on the rate of revisiting (the response variable) during the dispersal period of juvenile red squirrels.

\begin{tabular}{lllll}
\hline & Estimate & SE & $t$ & $p$ \\
\hline Dispersal distance & -0.0003 & 0.0001 & -2.57 & 0.02 \\
Study area & 0.92 & 0.36 & 2.57 & 0.02 \\
Sex & 0.54 & 0.24 & 2.23 & 0.03 \\
\hline
\end{tabular}

Rate of revisiting modeled as event/trial data with binomial distribution. Trial was the total number of visits made outside the natal site by the individuals. $p$ values considered significant $(p<0.05)$ are in italics study area, than in more natural conditions. One explanation for the tendency towards settling near built environment is the more diverse tree composition that may provide secondary food resources during low crop of spruce. Some of the observed areas around buildings contained more deciduous trees than the surrounding natural forest. There is often also additional feeding for birds near human settlement that red squirrels can utilize. Also, natural food resources may in some cases be more abundant in built areas, because the landscape is more fragmented, and singular trees therefore get more light for growth and seed production (Dylewski et al. 2016). However, if the preference for built environment would be dependent on only the edge effect on cone production, we should have noticed a preference also for forest edges, which was not the case in this study. Predator abundance can also influence on settlement decisions of dispersing individuals, but a previous study shows that for red squirrel, the proximity of goshawk nest or mammalian predator odor does not affect dispersal behavior in our study population (Selonen et al. 2018b).

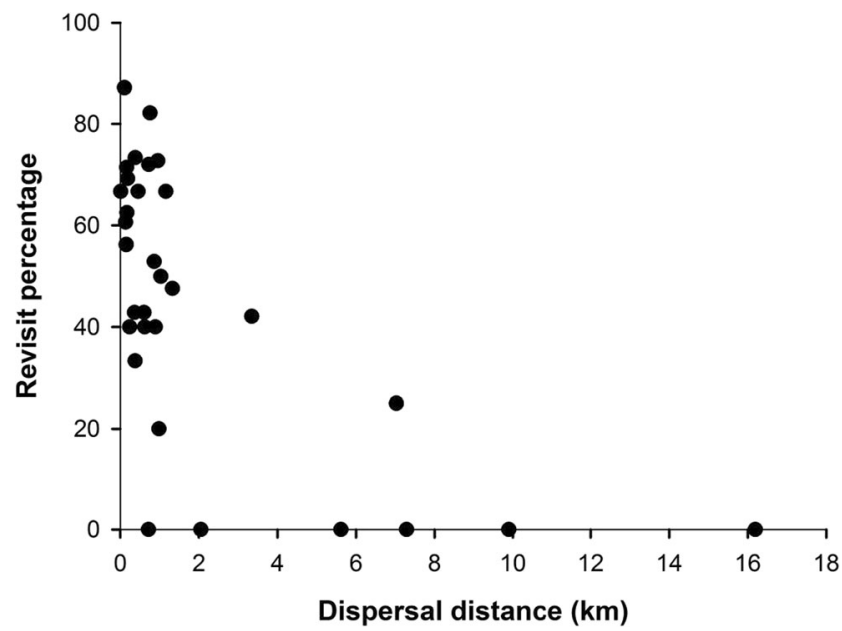

Fig. 1 Dispersal distance of each individual compared with the percentage of visits performed being revisits to previously entered sites during natal dispersal of the individual. Urban and rural study areas combined 
Table 3 The effect of landscape composition on the number of revisits (response variable with gamma distribution) to visited site during dispersal of juvenile red squirrels.

\begin{tabular}{llllll}
\hline & & Estimate & SE & $t$ & $p$ \\
\hline Turku & Coniferous & 0.002 & 0.14 & 0.01 & 0.99 \\
& Deciduous & -0.08 & 0.19 & -0.42 & 0.68 \\
& Grass & -0.006 & 0.18 & -0.03 & 0.98 \\
& Building & -0.12 & 0.16 & -0.76 & 0.45 \\
Asphalt & -0.13 & 0.08 & -1.64 & 0.11 \\
Edge density & 0.18 & 0.21 & 0.83 & 0.41 \\
Distance to natal nest & -0.13 & 0.16 & -0.82 & 0.04 \\
Selected/not & -1.20 & 0.32 & 2.80 & 0.02 \\
Sex & -0.08 & 0.23 & -0.36 & 0.73 \\
Visit total & 0.03 & 0.01 & 2.34 & 0.03 \\
Pine & 0.33 & 0.85 & 0.39 & 0.70 \\
Spruce & -0.71 & 0.63 & -1.12 & 0.27 \\
Young forest & 0.56 & 0.55 & 1.02 & 0.32 \\
Field & 0.08 & 0.36 & 0.23 & 0.82 \\
Built & -0.94 & 0.81 & -1.16 & 0.25 \\
Edge density & -0.99 & 0.56 & -1.76 & 0.09 \\
Distance to natal nest & -3.13 & 1.11 & -2.81 & 0.008 \\
Selected/not & -3.63 & 1.34 & -2.72 & 0.02 \\
Sex & 0.33 & 0.84 & 0.36 & 0.70 \\
Visit total & 0.33 & 0.14 & 2.26 & 0.04 \\
\hline \multirow{4}{*}{ Kauka } & & & & \\
& & & &
\end{tabular}

"Selected/not" indicates whether the site was selected for final settlement. "Visit total" is the total number of visits out from the natal site made by the individual. Individual ID was set as a repeated measure in the model

Average landscape variables measured for each visited site (Turku $n=$ 113 , Kauhava $n=81$; study areas were modeled separately) within a $25-\mathrm{m}$ buffer around each squirrel location of that site. $p$ values considered significant $(p<0.05)$ are in italics

Decision-making process during natal dispersal of red squirrel seems, however, to be driven mainly by other factors than landscape characteristics. Factors that we could not control include the changes in food availability: The instability of food resources has been observed to increase adult breeding dispersal rate of red squirrels (Lurz et al. 1997), and adults are observed to move between habitats depending on the food situation (Wauters and Dhondt 1992). Also population density affects dispersal of red squirrels because individuals prefer patches where same-sex density is lower (Wauters et al. 2010). The polygynous-promiscuous mating system of red squirrels (Lurz et al. 2005) may also explain that in the current study, females made less revisits during their dispersal than males. Breeding males move more than females and have larger home ranges in arboreal squirrels, because males move between territories of several females (Wauters and Dhondt 1992; Andrén and Delin 1994; Wauters et al. 2001; Selonen et al. 2013). That is, the higher breeding movement activity of males than females might be already related to revisit behavior
Table 4 The effect of landscape composition on the selection of settlement site (binomial model: settlement site vs. sites only visited and not used for settlement) during dispersal of juvenile red squirrels.

\begin{tabular}{llllll}
\hline \multirow{7}{*}{ Turku } & & Estimate & SE & $t$ & $p$ \\
& Coniferous & 0.02 & 0.24 & 0.09 & 0.93 \\
& Deciduous & 0.29 & 0.31 & 0.93 & 0.35 \\
& Grass & 0.34 & 0.46 & 0.74 & 0.46 \\
& Building & 0.36 & 0.53 & 0.68 & 0.50 \\
& Asphalt & -0.31 & 0.28 & -1.13 & 0.26 \\
& Edge density & 0.0002 & 0.002 & 0.08 & 0.93 \\
& Sex & 0.07 & 0.44 & 0.17 & 0.87 \\
& Pine & 0.14 & 0.39 & 0.37 & 0.72 \\
& Spruce & 0.03 & 0.35 & 0.10 & 0.92 \\
& Young forest & 0.49 & 0.42 & 1.15 & 0.26 \\
& Field & -0.54 & 0.31 & -1.75 & 0.088 \\
& Built & 0.95 & 0.46 & 2.07 & 0.047 \\
& Edge density & -0.54 & 0.33 & -1.65 & 0.11 \\
& Sex & -0.58 & 0.39 & -1.46 & 0.16 \\
\hline
\end{tabular}

Average landscape variables measured for each visited site within a $25-\mathrm{m}$ buffer around each squirrel location of that site. Analysis included 81 sites for 26 individuals in the rural Kauhava area, and 102 sites for 17 individuals in the urban Turku area. Study areas analyzed separately, see the "Materials and methods" section for description of landscape variables. $p$ values considered significant $(p<0.05)$ are in italics

during natal dispersal, despite the fact that dispersal distances do not differ between sexes or are longer for females than males in arboreal squirrels (for review, see Selonen and Mäkeläinen 2017). In other words, the search for potential future mates by males might increase their revisit behavior compared with that by females that likely base their habitat selection on factors determining the site's potential for raising offspring (Andersson 1994).

We conclude that our study gives evidence for dispersing animals actively comparing possible future settlement sites during their natal dispersal. However, individuals performing long movements perform less revisits during their natal dispersal, probably due to cost-related factors. Against our hypothesis, the landscape characteristics had only a minor effect on the settlement decisions of juvenile red squirrels. This indicates that mate and food resource availability, that previously have been found to affect settlement patterns of the species (Wauters and Dhondt 1992; Wauters et al. 2010), likely determine dispersal decisions of red squirrels. Nevertheless, our study supports the conclusion that revisiting behavior is linked to dispersal and varies between sexes and habitats of the species.

Acknowledgments We would like to thank the anonymous reviewers for their valuable comments on this manuscript. We thank Erkki Korpimäki for providing facilities of the rural Kauhava study area. We also thank Alexandre Villiers for providing landscape map for Kauhava study area and Tanja Hannola and Katariina Husman for their help in the field. 
Funding Open access funding provided by University of Turku (UTU) including Turku University Central Hospital. This work was supported by the Academy of Finland (grant number 259562 to VS), Turku University Foundation and the Finnish Cultural Foundation - South Ostrobothnia Regional fund.

Availability of data and material The datasets generated and analyzed during the current study are available from the corresponding author on reasonable request.

\section{Compliance with ethical standards}

Conflicts of interest The authors declare that they have no conflict of interest.

Ethics approval Ethical approval was not required for this study. All applicable international, national, and/or institutional guidelines for the use of animals were followed.

\section{Consent to participate Not applicable.}

Consent for publication The work in this manuscript is original research and not published or being considered for publication elsewhere.

Code availability Not applicable.

Open Access This article is licensed under a Creative Commons Attribution 4.0 International License, which permits use, sharing, adaptation, distribution and reproduction in any medium or format, as long as you give appropriate credit to the original author(s) and the source, provide a link to the Creative Commons licence, and indicate if changes were made. The images or other third party material in this article are included in the article's Creative Commons licence, unless indicated otherwise in a credit line to the material. If material is not included in the article's Creative Commons licence and your intended use is not permitted by statutory regulation or exceeds the permitted use, you will need to obtain permission directly from the copyright holder. To view a copy of this licence, visit http://creativecommons.org/licenses/by/4.0/.

\section{References}

Abrahams MV (1986) Patch use under perceptual constraints: a cause for departures from the ideal free distribution. Behav Ecol Sociobiol 19: 409-415. https://doi.org/10.1007/BF00300543

Andersson M (1994) Sexual selection. Princeton University Press, Princeton, NJ

Andrén H, Delin A (1994) Habitat selection in the Eurasian red squirrel, Sciurus vulgaris, in relation to forest fragmentation. Oikos 70:4348. https://doi.org/10.2307/3545697

Baker PJ, Harris S (2007) Urban mammals: what does the future hold? An analysis of the factors affecting patterns of use of residential gardens in Great Britain. Mamm Rev 37:297-315. https://doi.org/ 10.1111/j.1365-2907.2007.00102.x

Bonte D, van Dyck H, Bullock J et al (2012) Costs of dispersal. Biol Rev 87:290-312. https://doi.org/10.1111/j.1469-185X.2011.00201.x

Bowler DE, Benton TG (2005) Causes and consequences of animal dispersal strategies: relating individual behavior to spatial dynamics. Biol Rev 80:205-225. https://doi.org/10.1017/ S1464793104006645
Clobert J, Danchin E, Dhondt AA, Nichols JD (eds) (2001) Dispersal. Oxford University Press, New York. https://doi.org/10.1046/j.13652540.2001.0963a.x

Cote J, Bestion E, Jacob S, Travis J, Legrand D, Baguette M (2017) Evolution of dispersal strategies and dispersal syndromes in fragmented landscapes. Ecography 40:56-73. https://doi.org/10. 1111/ecog.02538

Dale S, Steifetten O, Osiejuk TS, Losak K, Cygan JP (2006) How do birds search for breeding areas at the landscape level? Interpatch movements of male Ortolan Buntings. Ecography 29:886-898. https://doi.org/10.1111/j.2006.0906-7590.04816.x

Danchin E, Heg D, Doligez B (2001) Public information and breeding habitat selection. In: Clobert J, Danchin E, Dhondt AA, Nichols JD (eds) Dispersal. Oxford University Press, NewYork, pp 243-258

Dingemanse NJ, Both C, van Noordwijk AJ, Rutten AL, Drent PJ (2003) Natal dispersal and personalities in great tits (Parus major). Proc $\mathrm{R}$ Soc Lond B 270:741-747. https://doi.org/10.1098/rspb.2002.2300

Dylewski Ł, Przyborowski T, Myczko Ł (2016) Winter habitat choice by foraging the red squirrel (Sciurus vulgaris). Ann Zool Fenn 53:194 200. https://doi.org/10.5735/086.053.0408

Fey K, Hämäläinen S, Selonen V (2016) Roads are no barrier for dispersing red squirrels in an urban environment. Behav Ecol 27:741-747. https://doi.org/10.1093/beheco/arv215

Hämäläinen S, Fey K, Selonen V (2018) Habitat and nest use during natal dispersal of the urban red squirrel (Sciurus vulgaris). Landscape Urban Plan 169:269-275. https://doi.org/10.1016/j.landurbplan. 2017.09.011

Hämäläinen S, Fey K, Selonen V (2019) The effect of landscape structure on dispersal distances of the Eurasian red squirrel. Ecol Evol 9: 1173-1181. https://doi.org/10.1002/ece3.4806

Haughland DL, Larsen KW (2004) Ecology of North American red squirrels across contrasting habitats: relating natal dispersal to habitat. J Mammal 85:225-236. https://doi.org/10.1644/BWG-113

Jokimäki J, Selonen V, Lehikoinen A, Kaisanlahti-Jokimäki MJ (2017) The role of urban habitats in the abundance of red squirrels (Sciurus vulgaris, L.) in Finland. Urban For Urban Green 27:100-108. https://doi.org/10.1016/j.ufug.2017.06.021

Lurz P, Garson PJ, Wauters LA (1997) Effects of temporal and spatial variation in habitat quality on red squirrel dispersal behavior. Anim Behav 54:427-435. https://doi.org/10.1006/anbe.1996.0486

Lurz P, Gurnell J, Magris L (2005) Sciurus vulgaris. Mamm Species 769: 1-10. https://doi.org/10.2307/3504523

Luttbeg B (2002) Assessing the robustness and optimality of alternative decision rules with varying assumptions. Anim Behav 63:805-814 https://doi.org/10.1006/anbe.2001.1979

Luttbeg B, Langen TA (2004) Comparing alternative models to empirical data: cognitive models of western scrub-jay foraging behavior. Am Nat 163:263-276. https://doi.org/10.1086/381319

Mabry K, Stamps J (2008) Searching for a new home: decision making by dispersing brush mice. Am Nat 172:625-634. https://doi.org/10. $1086 / 591682$

Morosinotto C, Villers A, Thomson RL, Varjonen R, Korpimäki E (2017) Competitors and predators alter settlement patterns and reproductive success of an intraguild prey. Ecol Monogr 87:4-20. https://doi.org/10.1002/ecm.1238

Nurmi T, Parvinen K, Selonen V (2017) The evolution of site-selection strategy during dispersal. J Theor Biol 425:11-22. https://doi.org/ 10.1016/j.jtbi.2017.05.002

Reed JM, Boulinier T, Danchin E, Oring LW (1999) Informed dispersal: prospecting by birds for breeding sites. Curr Ornithol 15:189-259. https://doi.org/10.1007/978-1-4757-4901-4_5

Schlaepfer MA, Runge MC, Sherman PW (2002) Ecological and evolutionary traps. Trends Ecol Evol 17:474-480. https://doi.org/10. 1016/S0169-5347(02)02580-6 
Selonen V, Hanski IK (2010) Decision making in dispersing Siberian flying squirrels. Behav Ecol 21:219-225. https://doi.org/10.1093/ beheco/arp 179

Selonen V, Mäkeläinen S (2017) Ecology and protection of a flagship species, the Siberian flying squirrel. Hystrix 28:134-146. https://doi. org/10.4404/hystrix-28.2-12328

Selonen V, Painter JN, Rantala S, Hanski IK (2013) Mating system and reproductive success in the Siberian flying squirrel. J Mammal 94: 1266-1273. https://doi.org/10.1644/13-MAMM-A-129

Selonen V, Fey K, Hämäläinen S (2018a) Increased differentiation between individuals, but no genetic isolation from adjacent rural individuals in an urban red squirrel population. Urban Ecosyst 21:10671074. https://doi.org/10.1007/s11252-018-0794-2

Selonen V, Fey K, Hämäläinen S, Turkia T, Korpimäki E (2018b) Do predators modify context-dependent dispersal of red squirrels? Behav Ecol Sociobiol 72:136. https://doi.org/10.1007/s00265-018-2554-y

Stamps JA (2001) Habitat selection by dispersers: integrating prox-mate and ultimate approaches. In: Colbert J, Danchin E, Dhondt AA, Nichols JD (eds) Dispersal. Oxford University Press, New York, pp 230-242
Turkia T, Selonen V, Danilov P, Kurhinen J, Ovaskainen O, Rintala J, Brommer JE (2018) Red squirrels decline in abundance in the boreal forests of Finland and NW Russia. Ecography 41:1370-1379. https://doi.org/10.1111/ecog.03093

Wauters L, Dhondt AA (1992) Spacing behaviour of red squirrels, Sciurus vulgaris: variation between habitats and the sexes. Anim Behav 43:297-311. https://doi.org/10.1016/S0003-3472(05) 80225-8

Wauters L, Gurnell J, Preatoni D, Tosi G (2001) Effects of spatial variation in food availability on spacing behaviour and demography of Eurasian red squirrels. Ecography 24:525-538. https://doi.org/10. 1111/j.1600-0587.2001.tb00487.x

Wauters LA, Verbeylen G, Preatoni D, Martinoli A, Matthysen E (2010) Dispersal and habitat cuing of Eurasian red squirrels in fragmented habitats. Popul Ecol 52:527-536. https://doi.org/10.1007/s10144010-0203-z

Publisher's note Springer Nature remains neutral with regard to jurisdictional claims in published maps and institutional affiliations. 